\title{
Reflections on Some Approaches \\ to Style and Stylistics
}

\author{
Norman F. Blake \\ University of Sheffield
}

Stylistics has become a familiar subject over the recent past, and this has inevitably resulted in a spate of books on the subject. They fall into two broad categories: one devoted to background material and the other to an analysis of one or more texts. The first category itself consists of two kinds of book: one in which the reader is assumed to have no knowledge of linguistics and the other in which some knowledge of linguistics is presupposed. It may be appropriate to consider first these various categories and their implications for those who want to get into stylistics.

I shall start by considering those background books which assume no linguistic knowledge on the part of the reader, of which The Language of Literature by M. Cummings and R. Simmons is a good example[1]. Because they assume the absence of any linguistic knowledge, such books must spend most of their time in providing it, for it is also a presupposition of such books that a familiarity with linguistics is a prerequisite for the stylistic study of literary texts. As the authors write in their preface "Since the means given to the student to describe literary language is the technique of linguistic description, this introduction to literature is also an introduction to the basic tools and basic concerns of linguistic analysis" (p. xv). The implication of this is that one cannot direct a reader to a grammar of the language to acquire the tools himself; he has to be provided with the tools in the same book in which he is shown how they can be used for a particular purpose. It is hardly surprising that a reader of such a book might well feel that more attention is given to the basic grammatical tools than to their application. 'The book by Cummings and Simmons deals in turn with phonology and phonetics, graphology, grammar, lexis and context in much the same way as any standard grammar of the language would. The question of whether all this information is necessary for a stylistic analysis of literary texts is not asked; equally it is not considered whether a methodological organisation which is suitable for grammar is appropriate for stylistics. It is possible that many. readers of this book who have no previous knowledge of linguistics will feel that they are being taught linguisties rather than stylisties, and consequently they may not get past the chapters on phonology and phonetics because they will fail to appreciate the relevance of this chapters to their own concerns. The detail which is provided is excessive and potentially self-defeating, and it provides the reader with no idea as to how he should start a stylistic analysis. 
It is also characteristic of these books that they should seek to inculcate a modern approach to grammar, either a systemic or a transformational generative one. The intention is to provide a grammatical basis, not to discuss which grammatical basis might be more appropriate for students of literature in making a stylistic approach. It could be argued that, because students with no knowledge of modern linguistics might nevertheless have some acquaintance with traditional grammar, it would be more sensible to base any stylistic approach upon what they know rather than what they do not. Modern grammars tend to pay more attention to sound and to syntax, with a downgrading.of lexis, for although traditional grammar is word-based modern grammars tend to be sentence-based. But most students find the lexis the most interesting part of style and this interest ought perhaps to be exploited as a way into stylistics. It is also characteristic of modern grammars that they focus on the modern language, and hence books introducing grammar for potential stylistics students tend to focus on modern language and literature. Modern grammars often lack a historical dimension, and modern books on style which introduce such grammatical models are the same. But most of the literature we read, whether as students in a university or as general readers, comes from the past and any approach to stylistics should pay due regard to this fact.

The second group of books on stylistics in our first category are those which assume some knowledge of linguistics on the part of the reader, usually the basic knowledge of clause components. These books inevitably tend towards the theoretical in an attempt to show the benefits of the application of linguistic theory to criticism|2|. Although they often contain acute analysis of particular passages, the analysis is usually less important than the applicability of the theory. Since some basic linguistics is understood, such books often work with aspects of linguistic theory which deal with units bigger than a sentence. Pragmatics, cohesion and discourse analysis are especially prominent. Some of the basic tenets of these approaches can often be grasped with little or no linguistic information about units smaller than a sentence. They often overlap with theoretical models proposed by literary critics, and indeed it could be suggested that books of this kind have as a goal the rapprochement between linguistic and critical theories. Antony Easthope in his book on Poetry as Discourse notes:

Linguistics, the science which takes language as its object, can show how an utterance lakes its place in the system of language at levels up to and including the sentence. It cannot show how and why one sentence connects with another into a cohesive whole: this is a matter of discourse . . Discourse, then, is a term which specifies the way that sentences form a consecutive order, take part in a whole which is homogeneous as well as heterogeneous|3].

This quotation underlines the reason for the differing arrangement of books in this group. Books introducing linguistics to students of style can follow a pattern which is that of formal grammars of the language, precisely because such information is susceptible to formal presentation. Beyond a sentence there are few, if any, formal rules, and this makes it difficult for writers to present a coherent body of knowledge. What they tend to present is an outline of a general 
approach and how that can be applied to style. It is for this reason that such books tend to veer towards theoretical discussions of criticism. Inevitably because such books assume some knowledge of linguistics and some sophistication in critical practice, they belong to what might be called a second tier of books on stylistics; they are not as a general rule suitable for those who are looking for an approach into style without much prior knowledge of it.

The second broad category of books about style $I$ isolated at the beginning of this paper consists of those books which contain analyses of particular literary works without necessarily explaining the philosophical or theoretical background to their approach. Naturally such analyses differ in their approaches and in the amount of detail they provide. At one end of the scale we have those books which try to provide a detailed linguistic inventory of the text they analyse. A book of this type is Shakespeare's Verbal Art in Th'Expence of Spirit by Roman Jakobson and Lawrence G. Jones[4]. Although a short book, this tries to give a full account of all the linguistic features of that Shakespearian sonnet. It deals in turn with such features as rhymes, spelling, pervasive features, odd against even, outer against inner, anterior against interior, and so on. Such of these features can hardly be said to be linguistic in principle, though they may be exemplified through particular aspects of language. For example, they write:

Within each of these two contiguous strophic pairs, anterior/posterior, grammatical contrasts between neighboring strophes play an incomparably wider role codd versus even and outer versus inner) than specific similarities in their grammatical structure $[5 \mid$.

In other words, structural contrasts between anterior and posterior strophes may be realised through grammatical features, and it would presuppose that a reader is sufficiently competent to detect those grammatical features in a text. In many cases it may well seem as though certain grammatical features are set in contrast with another because that is what the system demands and not because the contrast leads to a deepening of our understanding of how the poem works. There is too much information, and not all of it can be relevant to a critical understanding of a text. Clearly the approach adopted in this book is relevant only to poetry since so many of the features are poetic.

At the other end of this category are books which contain essays by different people, each of which is normally devoted to an analysis of a single text usually through focusing upon a single linguistic item[6]. The paradigm of this type of essay is Halliday's well-known analysis of the frequency of transitivity clause types in William Golding's The Inheritors[7]. This essay starts by raising the question of relevance:

This, it seems to me, is one of the central problems in the study of "style in language": I mean the problem of distinguishing between mere linguistic regularity, which in itself is of no interest to literary studies, and regularity which is significant for the poem or prose work in which we find it $[8]$. 
The approach to style must be through isolated features, it is implied, and not through the blanket coverage provided by Jakobson and Jones. But this does raise the problem of how a reader knows which linguistic feature is significant. This is likely to come only with sophistication in reading and critical awareness; and that in turn suggests that those who have little experience may find no help in stylistics because they will never know where to start their analysis. For those who choose to analyse a particular feature in a given text rarely explain why it is that feature rather than another which they have chosen. The choice is presumably based on a hunch which springs from their reading or re-reading of the text in question. It is unlikely that one would be able to offer beginners in stylisties any guidelines as to what features might be looked for in particular texts.

I do not wish to imply from this brief survey that the books that have been written on style are in any way lacking in usefulness; many of them are excellent for the purposes for which they were intended. It is rather my intention to highlight a problem that exists for those who feel they want to know something about stylistics, but do not know where to begin. Elementary books which provide an introduction usually provide an introduction to basic linguisties on the assumption that this is an absolute essential for anyone going into stylisties. They provide considerable information without going into the question of how any of that information can be applied, for when a beginner turns to books and articles which contain stylistic analyses they usually exploit only one of the many linguistic features outlined in elementary books of stylistics. There is a gap between the presentation of the basic linguistic knowledge and the application of that knowledge in particular cases. It may well be that one has to suggest that for beginners particular steps should be followed in any analysis, for even if they should not in themselves provide a good clue to the structure of the text in question they will probably throw up insights which may be developed through further analysis. In this one should probably also build upon what most users are familiar with, for it should not be part of the purpose of such an approach to suggest that it is available only to people with a profound knowledge of linguistics. Stylistic study is probably as much an attitude of mind as a specifically linguistic approach, for it is through that attitude of mind that one wants to find out more about linguistics to enrich one's reading of literature.

Any approach at this level should be suitable for a text written in any period of English and it should exploit the knowledge of the language which a reader has. This means that the starting point must be within the sentence rather than between sentences, for the principles of sentence discourse are as yet relatively unfamiliar to the average reader. My euperience as a teacher suggests that everyone is familiar with the basi principle 3 of organisation of a sentence into subject and predicate. Consequently one could suggest that the first step in any analysis should be to break down the sentences in the text for analysis into their clause elements. It is probably immaterial what terminology one uses, whether it is traditional or modern, provided one understands it and is consistent in its application. As it is very commonly employed in grammar today it might be wisest to employ the SPCA system, by which all sentences can be broken down into the elements subject, predicator, complement and adjunct. Not only is this 
system widely used today, but it has the advantage that the elements it handles are only four in number and so it is relatively easy to applyl9]. Some may prefer to modify it by breaking down the complement into two elements, namely object and complement.

A division of the text's sentences in this way should enable their structure to be revealed, though this will not in itself do more than provide some clues as to the reason for the way in which the content is presented. An essential next step is to go on from this analysis to consider how the information has been packaged, as it were. To do this it is desirable to think in terms of the concepts of theme, rheme and end-focus found in some modern grammars. These concepts are defined in varying ways by scholars, but I shall use them in the following way. Each clause has a theme, and the theme is the first element in the clause. If the order is SPCA then the subject is the theme; if the order is CSPA, then the complement is the theme; and so on. The rheme is made up of all the elements in the clause other than the first one which fulfils the function of theme. By end-focus I mean the final element in a clause, so that if a clause has a SPCA order then the adjunct will be in end-focus. Of these concests that of theme is more important than endfocus, though the two often work together. The definition of theme and end-focus is a formal one which is closely related to the division of the sentence into the SPCA elements. It may also be useful to bear in mind that some analysts consider topic and comment along with theme and rheme. The concepts of topic and comment are more difficult to handle and they are not formalised in the same way as theme and rheme, for the topic may be defined as the psychological subject of the sentence. It is that element of the clause which seems to be the central or psychological subject (i.e. what the sentence is about), even if it is not the grammatical subject. From the point of view of how the text is written, it is important to understand why what is the psychological subject is not also the grammatical subject. Here a word of caution is necessary, since not everyone will agree on what the psychological subject of a particular sentence is. This will become more apparent as we consider some examples.

What I have outlined so far is a possible mechanism for those who have little experience of handling style to use when they wish to explore the style of a text. It relies on very little basic knowledge of linguistics and equally it does not demand a high level of critical sophistication. It is time now to apply this approach to some examples, and I have chosen a Shakespearian sonnet and a passage from Jane Austen's Mansfield Park to provide variety of style and historical period. I shall consider Shakespeare's sonnet 129 first, which I have chosen because it was used by Jakobson and Jones. This should enable the two approaches to be compared. The sonnet is reproduced here as it occurs in the first quarto, with a single textual emendation:

1 'Th'expence of Spirit in a waste of shame

2 Is lust in action, and till action, lust

3 Is periurd, murdrous, blouddy full of blame

4 Sauage, extreame, rude, cruell, not to trust,

5 Inioyd no sonner but dispised straight,

6 Past reason hunted, and no sooner had 
7 Past reason hated as a swollowed bayt,

8 On purpose layd to make the taker mad.

$9 \mathrm{Mad}$ in pursut and in possession so,

$10 \mathrm{Had}$, hauing, and in quest to haue extreame,

11 A blisse in proofe and proud and very wo,

12 Before a ioy proposd behind a dreame,

13 All this the world well knowes yet none knowes well,

14 To shun the heauen that leads men to this hell[10].

Within this sonnet there are two sentences, lines 1-8 and 9-14, but they both consist of two parts. The first sentence can be divided into two clauses separated by the and in line 2 , so that the first clause consists of lines 1-2a and the second of lines $2 \mathrm{~b}-8$. The second sentence is divided by the yet in line 13 , so that the first clause consists of lines 9-13a and the second of lines 13b-14. Even this basic division shows a structure emerging for the sonnet, which begins and ends with clauses of one and a half lines each and which has two long clauses within the middle so that a mirror structure is suggested of short:long - long:short clauses. Let us now consider the make-up of the individual clauses.

The first clause is relatively simple consisting of a straightforward SPC structure. This means taking the prepositional phrase in a waste of shame as part of the subject and in action as part of the complement. Naturally Th'expence of spirit in a waste of shame is not only the subject, but also the theme. Whether it is also the topic is more difficult to decide, as it frequently is with verbs like to be. It seems more acceptable to understand the topic as lust in action, since that appears to be the main subject of the clause as well as of the sonnet as a whole. The second clause has a structure very similar to the first except that it has an adjunct beginning. Its structure is ASPC. The introductory arrangement of this clause has been partly dictated by the wish to construct a mirror structure to the first clause and partly to provide a line which has a second half which inverts the first half. Hence lust which is the partial complement of the first clause becomes the subject of the second, and in action in the first clause is mirrored by till action in the second. But in the second clause the till action precedes the subject and so forms an adjunct, whereas in the first clause in action is part of the complement. This means that the structure of the first two clauses could be represented as " $\mathbf{a}$ is $\mathbf{b}$ and $\mathbf{b}$ is $\mathbf{a}$." However, in the second clause the complement is exceedingly long for it stretches over six lines. This arrangement is dictated by the need of the sonnet as a whole in that the second sentence, as we have seen, mirrors the first, and this in turn explains why the first clause in the first sentence did not thematize the topic. The overall structure demands that the first topic should come in the complement position. Equally it is unlikely that an author would place a long introductory theme which was not the topic at the beginning of a poem, and so the theme in the first clause is relatively brief. 'The two predicators are identical and indicate a state.

The complement of the second clause is long. It is made up at first of single words or short phrases (lines 3-4) which appear to be presented in no particular semantic order. They do not represent an ascending or descending order of hatefulness. But the last four lines (5-8) are set up as pairs in which the exces- 
sive urge to satisfy lust is matched by the great disenchantment which follows upon its satisfaction. One such contrast is embodied in line 5 and another in the final three lines of the sentence. This means that the complement gradually becomes more ponderous in structure for single words and phrases are followed by a one-line contrast, and in turn is succeeded by a three-line contrast. The single words and phrases at the beginning of the complement provide a yardstick against which one judges the contrasts in its second half, and in these contrasts it is always the disenchantment which comes at the end and so that provides the note on which the sentence finishes. The final word of the sentence is mad which could be said to form the end-focus of the sentence, and it stands in an influential relationship with the theme of the first clause, Th'expence of Spirit in a waste of shame.

The first clause of the second sentence extends from line 9 to line 13a, but its structure is different from those found in the first sentence. Here the clause starts off with a long complement, which is brought together in the final part of the complement as All this. The structure of this clause is CSAP. The second clause is introduced by yet, which although a co-ordinating conjunction is far more adversative in its implications than the and in the first sentence which is a straight forward linking word. This adversative conjunction prepares the reader for the final clause which can thus act as a summation of the sonnet as a whole. The structure of this secons clause is SPAC. The predicator and adjunct are identical in both clauses and provide a further linking mechanism. But the two subjects are the world and none, which are in contrast with each other as implied already by the adversative yet. The final complement occupies a complete sentence just as the initial subject has done.

The opening complement of the second sentence extends just over four lines and mirrors the final complement of the first sentence. This link is emphasised because the firs word Mad of the second sentence is also the last word of the first. In addition the extreame of line 10 picks up the same word in line 4 . Although the links between the final complement of sentence one and the first complement of sentence two are clearly marked out, there are some differences in their structure and effect. The first complement consisted of two lines of single words and phrases; nothing equivalent is found in the second. In the first complement the final contrast spills over three lines, whereas in the second each contrast occupies a single line and is confined within it. Each of the four contrasts in the second complement is built up of the similarity of the chase to its aftermath, but some of the words used are much gentler, even more optimistic than those used in the first complement. Words like blisse, ioy and dreame give a very different quality to the second sentence from that characteristic of the first. There are thus parallels and contrasts between the complements of the first two sentences. Having presented a position in the first sentence, Shakespeare is able to develop a long introductory complement in the second because the information contained in it is not new. This means that the complement is thematized in the second sentence.

The second clause in the second sentence has SPAC structure as we have seen. The subject of this none clause is thematized and is thus thrown in particular prominence and is contrasted with the world. The emphasis on none means 
that the sonnet finishes on a somewhat pessimistic note. This is accentuated by the end-focus which falls on hell, which with 'Th'expence of Spirit in a waste of shame at the beginning seems to form a kind of envelope in which the rest of the sonnet is packaged. 'The final complement is different in structure from any which has occurred hitherto since it consist not only of the typical parallel structure of the other complements (in this case setting heauen and hell against each other), but also of a relative clause dependent upon heauen. 'This relative clause contains its own subject that and predicator leads, but the nature of the predicator is different from all others in the sonnet. Most complements contain only non-finite verbs, which cannot form predicators. The main clauses which have predicators have is in the first sentence and knowes in the second. These are not action verbs, since they imply a state of being or knowledge. The verb in the final complement is an active verb, and is thus the only such verb in the sonnet. It makes the force of these predicator much stronger.

In what has been written above it should be apparent that a relatively simple methodology such as breaking down the clauses into their SPCA organisation has revealed a considerable amount about the structure of the sonnet and has suggested what other aspects might be investigated. The parallelism of the clause structure is reinforced by the words used, and this could lead on to an investigation of the vocabulary of the sonnet. Such an investigation could focus not only on the semantic implications of the vocabulary, but also the different types of verb used in the various clauses. We need now to see whether a similar analysis of a prose text is just as promising in its suggestiveness for further investigation. First I quote the opening lines of Mansfield Park, which I shall use as my example of prose.

(1) About thirty years ago, Miss Maria Ward of Huntingdon, with only seven thousand pounds, had the good luck to captivate Sir Thomas Bertram of Mansfield Park, in the county of Northampton, and to be thereby raised to the rank of a baronet's lady, with all the comforts and consequences of an handsome house and large income. (2) All Huntingdon exclaimed on the greatness of the match, and her uncle, the lawyer, himself, allowed her to be at least three thousand pounds short of any equitable claim to it. (3) She had two sisters to be benefited by her elevation; and such of their acquaintance as thought Miss Ward and Miss Frances quite as handsome as Miss Maria, did not scruple to predict their marrying with almost equal advantage. (4) But there certainly are not so many men of large fortune in the world, as there are pretty women to deserve them. (5) Miss Ward, at the end of half a dozen years, found herself obliged to be attached to the Rev. Mr. Norris, a friend of her brother-in-law, with scarcely any private fortune, and Miss Frances fared yet worse. (6) Miss Ward's match, indeed, when it came to the point, was not contemptible, Sir Thomas being happily able to give his friend an income in the living of Mansfield, and Mr. and Mrs. Norris began their career of conjugal felicity with very little less than a thousand a year|11|.

I have numbered each sentence at its beginning, though many of them contain more than a single clause. Indeed it is noticeable how all the sentences except the first consist of two clauses. Most of these are co-ordinating clauses linked by and, but the fourth sentence has a different structure which is accentuated by its being introduced by But. These two features tend to set this sentence somewhat 
apart from the others. The first sentence does have a parallel structure using and, but this links the qualifiers dependent upon the noun luck; to captivate and to be raised both depend on it. This structure which runs through the passage suggests that parallelism and contrast may well form important elements in an analysis. Most of the sentences tend to have a relatively simple structure, with the elaboration coming in the expansion of the clause elements as was true of the Shakespearian sonnet.

The first sentence opens with an adjunct, About thirty years ago. This is precisely how one might expect a narrative to begin, for a standard opening might well be Once upon a time. The adjunct of time distances the story and because it is thematised indicates that, to understand the present, details of the past have to be provided. 'The grammatical subject and the topic of the sentence are Miss Maria Ward of Huntingdon, with only seven thousand pounds. This is a typical opening subject in that it consists of a nominal group with its qualifier. We normally expect the first nominal group to tell us something about the hero or heroine of the story which is to follow. In fact it turns out that Miss Maria Ward is not the heroine, for the adjunct makes it clear that the first paragraph is filling in background details of thirty years ago. The qualifier does, however, set the scene in an important way. It indicates that Miss Ward has only seven thousand pounds and thus suggests to the reader that one of the most important, because one of the first, details to be indicated about any character is his or her wealth. Money, it is implied, is going to be an important feature of character evaluation. The complement of the first sentence reinforces this general impression, for its parallel nature indicates firstly the capture of Sir Thomas Bertram and secondly the financial and social implications of that conquest. The qualifier with all the comforts and consequences of an handsome house and large income matches the earlier with only seven thousand pounds.

The second sentence has its own parallel structure, for it consists of two simple declarative statements each with an SPC organisation. The grammatical subject of each clause is not what one might have expected, since the topic in each case is the greatness of the match and Miss Ward's insufficient claim to it. Instead, the grammatical subject and theme have been made the bystanders of the match, as it were, so that emphasis may fall upon the impact it had upon those in the vicinity. Hence All Huntingdon and her uncle, the lawyer, himself are thematised. The nominal groups are accentuated by the introduction of all and himself which suggest the width and depth of the response. The topic of each of the clauses has been put into end-focus so that greatness of the match and equitable claim to it parallel each other and receive considerable emphasis.

In the third sentence there is once more a parallel construction; in this case the two clauses are separated by a semi-colon. The subject of the first is she, namely the Miss Ward who had been the subject of the first sentence; but the subject of the second is the long group such of their acquaintance as thought Miss Ward and Miss Frances quite as handsome as Miss Maria relates more to the second sentence, for it refers to the onlookers of the match made by Miss Maria Ward. This third sentence thus unites the approach adopted by the first two sentences in that it refers both to the married sister and to those who 
witnessed it. It also introduces new material since it brings the two sisters into the story for the first time. These two are the complement of the first clause, although that complement continues with the words to be benefited by her elevation. As soon as the sisters are introduced they are mentioned as people who ought to draw financial benefit from their sister's marriage by marrying well themselves. It is implied that their introduction into a higher stratum of society would promote their chances of a rich marriage. The complement of the second clause to predict their marrying with almost equal advantage echoes the qualifier of the first complement to be benefited by her elevation. Both clauses end with expressions which underline the financial advantages of marriage, her elevation and equal advantage.

The fourth sentence is arranged in two parts each of which has a SPC structure. The SP in each case is there are so that the parallel structure is clearly brought out. This puts each complement into focus and makes them stand in contrast to each other, men of large fortune and pretty women to deserve them. In the first clause the in the world, which might be thought unnecessary, underlines the dearth of rich men by saying that there are insufficient men even in the whole world. The emphasis on in the world here tends to repeat that undercurrent of exaggeration which was introduced by the all in All Huntingdon. In the second clause there is naturally a relationship between the concepts pretty and deserve, for it is implied that women deserve rich husbands in relation to their beauty and for no other reason.

The structure of this sentence echoes that of the qualifier in the first clause of the preceding one, as thought Miss Ward and Miss Frances quite as handsome as Miss Maria, and this is a further example of the interlocking nature of these early sentences in the novel. It helps to show how carefully constructed this passage is.

The fifth sentence continues the parallel structure of the rest of the paragraph, dealing as it does first with one of the remaining two sisters and then with the other. Whereas up to now it had seemed as though the sisters were equal in expectation, it becomes apparent that the marriages of the sisters reflect their seniority in the family. The eldest had done very well; the second will do less well; and the third fares very badly. This development is put forward in the parallel structure of the two clauses of this sentence in which each sister acts as the subject and theme of each clause in turn. In order to place Miss Ward in the theme position to put it into contrast with Miss Frances, it is necessary in the first clause to put the adjunct at the end of half a dozen years second. This contrasts with the opening sentence in which the adjunct comes at the beginning. The function of that adjunct was to distance the whole paragraph; whereas the one in this sentence is merely indicating the passage of time which is less important within the general framework of the paragraph and so does not need special emphasis. But this adjunct has to be placed second so that the clause can end with the phrase with scarcely any private fortune. Although this phrase is a qualifier to the nominal group which has Mr Norris as its head, it is thrown into prominence by end-focus. The second clause in this sentence is briefer than the first. Its organisation parallels that of the first clause with Miss Frances set against Miss Ward and yet worse against with scarcely any private 
fortune. The parallelism emphasises the disparity in length between the two clauses, and suggests that Miss Frances does not need much time devoted to her because she has sunk solow in social life.

The sixth sentence of the opening paragraph helps to show that the marriage of the middle sister was not so poor after all. Its subject is Miss Ward's mateh. In this sentence the match is made the subject of the sentence, unlike the position in sentence two where the greatness of the match was the topic but not the grammatical subject. In this way Miss Ward's match is seen to be far less satisfactory than Miss Maria's. Nevertheless, it is not contemptible, for the first clause of this sixth sentence has an income in the living of Mansfield in end-locus and the second clause has with very little less than a thousand a year in end-focus. Money is shown to be important again by the parallelism between the two clauses and by the use of end-focus to highlight it.

Enough has been written perhaps to show that taking such a relatively straightforward feature as the arrangement of clause elements can lead to insights into the text. In Mansfield Park it has highlighted the position of money and it leads to some understanding of how Jane Austen organises the irony of her text. It suggests that a reading of the whole novel might take into account features of this sort to show the careful organisation of the language and the disposition of style to produce ironic overtones. What students who are relatively inexperienced readers of literary texts need is some way into analysis. The approach outlined here may provide them with that, and through this kind of analysis lead them on to understand what features in the text may benefit from further investigation. This type of analysis is not to be considered as the culmination of stylistic investigation; it is merely one way into the text which readers may find helpful.

NO'T'LS

1. Michael Cummings and Robert Simmons, The Language of Literature: A Stylistic Introduction to the Study of literature (Oxford: Pergamon Press, 1983 ).

2. For example, Roger Fowler, Linguistic Criticism (Oxford: Oxford University Press, 1986).

3. Antony Easthope, Poetry as Discourse (l.ondon: Methuen, 1983), p. 8.

4. Roman dakobsen and Lawrence G. Jones, Shakespeare's Verbal Art in 'Th'Expence of Spirit, De Propietatibus Litterarum Series Practica 35 (The Lague: Mouton, 1970).

5. Op. cit., p. 25. 
6. Various collecions of these texts exist. One of the more recent is Ron Carter, ed., Language and Literature (London: George Allen and Unwin), 1982.

7. M. A. K. Halliday, "linguistic Function and Literary Style: An Inquiry into the Language of William Golding's 'The Inheritors," in Donald C. Freenan, ed., Essays in Modern Stylistics (London and New York: Methuen, 1981).

8. Op. cit., p. 325.

9. These terms are explained in many introductions to language, as in Margaret Berry, Introduction to Systemic Linguistics 1: Structures and Systems (London: Batsford, 1975), pp. 62-71.

10. Edited from the 1609 quarto with the emendation of Made to Mad at the beginning of line nine.

11. Jane Austen, Mansfield Park, edited by J. Lucas with textual notes by J. Kinsey (London: Oxford University Press, 1970), p. 1. 